\title{
Considerations on cervical anastomoses in postcaustic esophageal reconstruction
}

\author{
Irina Predescu', Dragos Predescu' ${ }^{2}$, Codrut Sarafoleanu ${ }^{1,3}$, Silviu Constantinoiu ${ }^{2,3}$ \\ ${ }^{1}$ ENT\&HNS Department, "Sfanta Maria” Hospital, Bucharest, Romania \\ ${ }^{2}$ Department of General and Esophageal Surgery, "Sfanta Maria” Hospital, Bucharest, Romania \\ 3"Carol Davila" University of Medicine and Pharmacy, Bucharest, Romania
}

\begin{abstract}
BACKGROUND. The increased incidence of accidental or non-accidental ingestion of corrosive substances or drug compounds leading to postcaustic esophagitis represents a major public health issue. The treatment of postcaustic esophagitides is difficult and long lasting, calling for a complex team trained in this borderline pathology: gastroenterologist, general surgeon, otorhinolaryngologist, anesthesiologist, psychiatrist. In cases when preventive treatment has failed, the only effective therapy remains the surgical one.

MATERIAL AND METHODS. Our study involved an analysis of the cases treated and/or operated in the Department of General and Esophageal Surgery of the "Sfanta Maria" Hospital in Bucharest, between 1981-2014; respectively 195 patients who benefited from reconstructive esophageal interventions. Of the selected patients, 191 were operated for corrosive pathology produced by ingestion of caustic soda and only four cases by ingestion of acids. The lesion balance showed that, besides the esophagus, the oropharynx (28 patients), the larynx (7 patients) and the stomach (31 patients) had been affected by the corrosion process, requiring particular surgical solutions. The bypass reconstruction (preserving the esophagus) was the standard treatment, esophagectomy having been performed in only 4 patients.

RESULTS. The main remote postoperative complaint was feeding inability, a consequence of various causes: cervical anastomosis stenosis, motor dysfunctions of the graft or of the laryngopharyngeal complex, over-time alteration of the graft, technical vices or the degradation of intra-abdominal assemblies, traumatic injuries of the presternal substituent.

CONCLUSION. One of the most important moments during the esophageal reconstruction surgery remains the duration of the cervical anastomosis, since the postoperative complication rate and the remote functional outcome depend on it. Minimizing postoperative risks and complications requires a complete mastery of surgical methods, of the small technical "artifices" and of the necessary therapeutic refinements adapted to each individual case.

KEYWORDS: postcaustic esophageal lesions, esophageal reconstruction, cervical anastomosis, restoration of the deglutition.
\end{abstract}

\section{INTRODUCTION}

Postcaustic esophagitides, a consequence of accidental ingestion or for suicidal purpose of certain corrosive substances or some drug compounds administered per os, continues to represent a significant public health problem. The difficulty of the pathology due to post-ingestion requires a complex, homogenous, efficient team that includes: surgeon, gastroenterologist, otorhinolaryngologist, radiologist, anesthesiologist and, last but not least psychiatrist.
A caustic substance is any substance producing damage or destruction of the tissue in contact with the latter; they may be acids (hydrochloric, sulphuric, used as bath disinfectants, as descalers/strippers or when handling car accumulators), or alkalis (sodium hydroxide, hypochlorites, detergents with a high content of alkalis). The lesion induced by acid corrosives is the coagulation eschar, a barrier with a partially protective role for the deeper esophageal layers, while in case of alkali ingestion, due to their tissue penetrability, a liquefactive necrosis occurs, with severe parietal destruction. 
In our country, the use of caustic soda for the manufacture of soap, especially in rural areas, leads to relatively frequent accidents due to the ingestion of this corrosive (incidental, suicidal or in alcoholics). After the initial phase, with the occurrence of the liquefactive necrosis, the patient has a short stage in which he can feed quasi-normally and then a progressive dysphagia occurs. At that moment, most patients will benefit from dilation sessions with plugs or an endoscopic dilation balloon. Afterwards, some time after caustic ingestion, the definitive dilation treatment is addressed to elderly patients, vicious ones or those with moderate strictures.

Preventive treatment of scarring sequelae and lesions after caustic ingestion has failed, although various methods have been tried (corticoids ${ }^{1-4}$, D-Penicillamine ${ }^{3-5}, \mathrm{~N}$-acetylcysteine ${ }^{3-5}$ ), without being validated in humans. It has also been tried keeping an esophageal probe, but the complications were redoubtable - perforations and aggravation of lesions due to reflux.

Dilator treatment failure or esophageal perforation accidents bring the patient in specialized clinics, in order to attempt a reconstructive therapy. The indication for reconstruction is clearly specified: rapid occurrence of dysphagia after the dilation sessions; in patients with multiple dilation sessions in antecedents; in those with complications after dilation, malignization, perforation; in those in which dilation is impracticable; in patients with multiple stenotic lesions; in young people, with higher life expectancy and rapid postoperative recovery capacity.

Several techniques for esophageal reconstruction are described, but none is standardized, each case having its particularity, the option for a technique or another being made after careful analysis.

\section{MATERIAL AND METHODS}

Our study involved an analysis of cases treated and/ or operated in the Department of General and Esophageal Surgery of the "Sfanta Maria" Hospital in Bucharest, between 1981-2014; respectively, 195 patients who benefited from esophageal reconstructive interventions.

In order to improve the functional outcome and, certainly, the vital one, preoperative patient preparation was based on a number of well-established principles. Therefore, between the moment of ingestion and the surgical repair we waited about 7-8 months, the time needed for the cicatricial lesions to be defined $^{6}$. The occurrence of dysphagia made necessary the installation of a jejunostomy or a gastrostomy feeding device (preferably a jejunostomy, due to the potential ascension of the stomach for a possible reconstruc- tion). Preparing a metabolic reserve fund was achieved by establishing a hypercaloric diet (2500-3000 calories/day) and/or repletion by intravenous administration of certain lipo-amino-carbohydrate substituents in case of inability or difficulty in swallowing. The metabolic-nutritional assessment is compulsory, comprising data on weight loss, food intake, the existence of possible simultaneous pathologies (e.g. gastro-esophageal reflux). Concomitantly, correction of vices, smoking and alcohol ban were important. Meanwhile, patients were monitored, by conducting periodic clinical and paraclinical examinations: digestive endoscopy balance, ENT lesion balance, contrast radiological examination and tracheobronchial evaluation. Last but not least, the patient must be psychiatrically evaluated.

Although numerous methods of visceral preparation of a neo-esophagus are described, all of them being used in our clinic, we noted the preference for three main types of reconstruction: until the '90s, stomach tubulation according to the Gavriliu I or II procedure was preferred, but after this period, the left transverse colon or the entire stomach were preferred. The by-pass reconstruction (preserving the esophagus) was the standard treatment, esophagectomy having been performed only in 4 patients. The esophagoplasty technique, a term currently suggesting the use of a gastric antral or colonic patch with a nourishing pedicle $^{7-10}$, has not entered in the therapeutic arsenal.

Of the selected patients, 191 were operated for corrosive pathology produced by ingestion of caustic soda and only four cases by ingestion of acids. The lesion balance showed that, besides the esophagus, the oropharynx (28 patients), the larynx ( 7 patients) and the stomach (31 patients) had been affected by the corrosion process, requiring particular surgical solutions.

The lesional type associated with postcaustic esophagitis comprised:

- Cicatricial lesions of the vocal folds

- Immobility of the vocal cords

- Hypopharynx obstructions of stenotic nature

- Cicatricial amputation of the glottis

- Funnel-shaped stenoses of the hypopharynx

- Gastro-duodenal cicatricial involvement.

\section{RESULTS}

The main remote postoperative complaint was feeding inability, a consequence of various causes: cervical anastomosis stenosis (the most frequent situation), motor dysfunctions of the graft or of the laryngopharyngeal complex, over-time alteration of the graft, technical vices or the degradation of intra-abdominal assemblies, traumatic injuries of the presternal substituent. 
The occurrence of anastomotic stenoses - 21 cases - had as an etiological cause the emergence of an early postoperative cervical fistula, all these patients presenting this type of complication in a range of 5 to 7 days after the substitutive intervention. There was only one exception: in one of the cases given the large size of the cervical anastomosis, a major stenosis to alter deglutition din not occur. There were no stenoses except for the fistular complication. The therapeutic resolution was somewhat different - dilation, respectively surgery. Thus, in 17 patients, the dilation procedure was considered a success, initially with SavaryGilliard dilators, respectively, after acquiring the necessary equipment, by endoscopic pneumatic dilations (Figure 1). There were no complications with perforation, and we have not encountered any other inconvenience due to the technique used. For the rest of 4 patients, a reanastomosis was required because of the impossibility of using the dilation therapy, of its inefficiency over time or with short repetitive interval.

The complication with minimal chances of resolution is that of alteration of the deglutition mechanisms, usually in high anastomoses with the pharynx or in case of oropharyngeal burns - 16 patients, with difficulties of varying degrees of the pharyngeal deglutition time.

\section{DISCUSSIONS}

The most delicate moments of a reconstructive technique are the preparation of the visceral graft, respectively the duration of the cervical anastomosis, although any intraoperative inappropriate gesture may irreversibly vitiate the therapeutic and functional outcomes. Without insisting upon constructing the

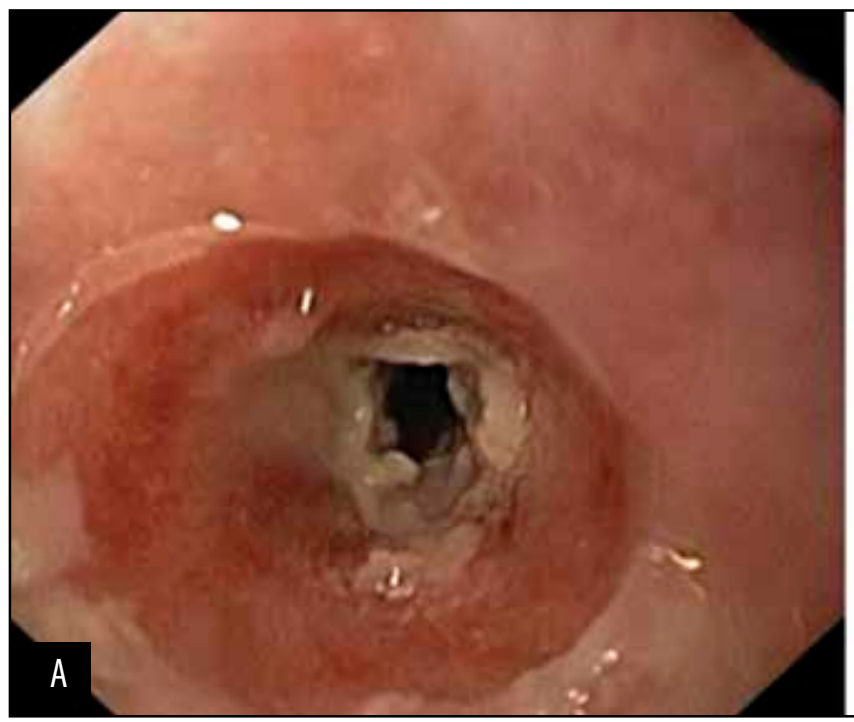

Figure 1 A - Endoscopic appearance of a benign stenosis, with food residue, fibrinous deposits and esophagitis. B - Endoscopic appearance during balloon dilation

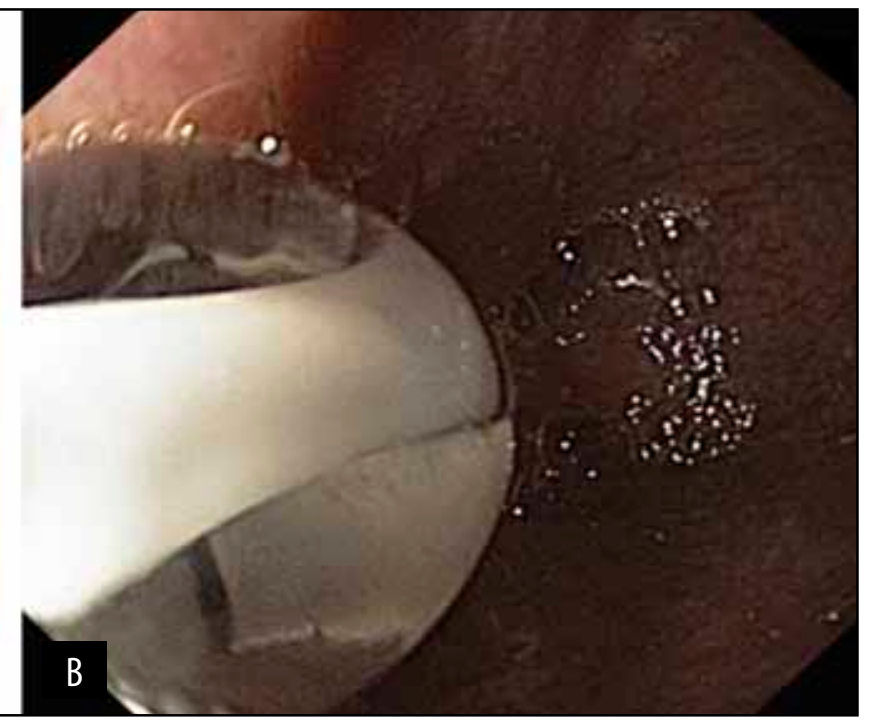

neo-esophagus, we will focus and make some considerations especially on the other essential operative time, keystone in terms of the postoperative complications rate and also regarding the functional outcome, namely the anastomosis of the graft in the cervical partner, either the esophagus or the hypopharynx.

If only 8-10 years ago it was stated about the eso-digestive anastomosis that it was as if "suturing the unsuturable"11, despite obvious new acquisitions, the results of post-anastomotic fistular complications still have not significantly improved ${ }^{12}$.

The extensive study of causes that transform the esophagus in a particular case from an anastomotic point of view enabled the identification of special conditions compared with the other digestive viscera:

- mediocre histological structure (no distinct serosal covering on its entire length unlike other gastrointestinal tract areas; the muscular layer poorly developed);

- precariousness of the esophageal vascularization compared to the rest of the digestive tract (probably the result of adaptation to the decreased function of this segment for the economy of the organism). The aphorism expressed by $\mathrm{D}$. Radulescu ${ }^{13}$ according to which "the entire esophagus has a parsimonious irrigation, the necessary minimum, as compared to the over- necessary vascularization of the stomach or to the so generous one of the bowel" is, I think, at least justified;

- difficult approach and technical execution conditions.

It is therefore no wonder that, even in the most experienced hands, anastomotic complications may occur. They have brought a "bad" reputation to the anastomoses with the esophagus, regardless of the 
level or its anastomotic partner. Some surgeons ${ }^{14,15}$ have even stated that "the esophagus is the most pitiless digestive viscus in terms of the anastomotic technique" and that is why they have proposed a series of compulsory principles to follow ${ }^{14}$ :

- draining of any superior aero-digestive septic foci;

- minimum contamination of the surgical field;

- adequate exposure;

- esophageal mobilization "to the necessary extent" (neither too wide so as to devascularize the slice, nor minimum to hinder the anastomosis technique);

- avoidance of the clampage, regardless of the instrument used;

- the presence of active bleeding in the anastomotic slices;

- correct mucosa-to-mucosa alignment;

- lack of pressure at the level of the anastomosis line;

- use of high-quality suture material (slowly absorbable monofilament or plurifilament, 3.0 or 4.0 , with an atraumatic needle) ${ }^{16-19}$;

- providing stitches at a distance of 3-4 $\mathrm{mm}$ between the threads and about 5-6 $\mathrm{mm}$ from the edge of the slices;

- the needle passes through the entire layer on the esophagus and sero-submucosally on the digestive partner in the monolayer suture.

In order to minimize the risk of anastomotic fistula, I insist on two elements that are absolutely compulsory: a good circumferential exposure of the cervical esophagus and a sufficient length so as to allow for a suture "in sight", after identifying the entire parietal stratigraphy.

Whenever possible, an anastomosis with the esophagus is preferable from a functional point of view, but a series of post-caustic lesions may compromise the digestive duct. In this case, the only option is a high anastomosis, with the hypo- or even the oro-pharynx.

\section{Characteristics of eso-visceral anastomosis}

Usually, the cervical anastomosis of the graft to the esophagus is performed in a termino-lateral manner (T-L). The execution of the stoma on the graft is performed specifically: (i) for the stomach, the site of choice is as high as possible on the apex, but preserving a small cranial segment; (ii) for the jejunum, longitudinally, on the anti-mesostenic edge, at about 3-4 $\mathrm{cm}$ from the post-sectional suture line; (iii) for the colon, still at the same distance from the section edge but on the teniae coli. It is important to ensure a dimension as superimposable as possible of the two anastomotic partners.

Using for grafting some viscera with different anastomotic characteristics and behaviour justifies the presentation of certain small technical details and variants specific to each type of suture.

The eso-gastric anastomosis is only performed in the termino-lateral (T-L) manner, both manually and mechanically. A recommended option ${ }^{20,21}$ would be to create an oblique anastomosis orifice, with valvular role, obtained by longitudinal cutting of the esophageal stump on about 2-3 cm, followed by the suture with the everted mucosa of the two esophageal flaps. The technique of an invaginated anastomosis, initially supported by Lorta-Jacob, namely an anti-reflux valve with additional protection of the anastomosis, involves oblique cutting of the greater tuberosity, followed by suture of the posterior esophageal slice. The anterior gastric flaps will be sutured anteriorly to the esophagus, with closure of the gastric excess and a plication over the eso-gastric suture. Chinese authors have simplified $i^{22}$, eliminating the duration of the fornix resection by classically implanting and anastomosing the graft, after which they "sleeve" the anastomosis by the invagination produced by passing circumferential esogastric sero-serous threads, at a distance of $1-1.5 \mathrm{~cm}$ from the suture line. Chinese surgeons have also reported another method, namely de "tunnelling" of the anastomosis $^{23}$. In the gastric tube anastomosis, the implantation is of termino-terminal type (T-T).

The eso-jejunal anastomosis or eso-ileal anastomosis has the reputation of the most "convenient" situation compared to the other anastomotic partners of the esophagus, the execution being of T-T or T-L type; the first is preferable especially in the case of an apparent congruence of the two partners.

The eso-colonic anastomosis is the most precarious of all types of eso-visceral sutures (Figure 2, Figure 3). This is due to the parietal gracility, the vascular but also septic factor of the colon compared to the stomach or the jejunum. Usually, the method is T-L and only exceptionally T-T (convenient caliber of the loop).

An increasingly more attractive anastomotic variant is the one using mechanical suturing devices. From a historical point of view, the most common technique is that using circular staplers and allowing to perform T-T or T-L anastomosis ${ }^{24,25}$. The circular stapler has provided consistent results over time, representing an effective method, quick and relatively accessible from a technical point of view. Beginning with the 80 s, one has developed anastomotic techniques perfected by linear mechanical suturing devices (linear cutting stapler). Such a variant is that of a T-L anastomosis with a sectional linear stapler ${ }^{26,27}$. Lately, both mechanical and manual hybrid, mixed techniques have gained ground.

In situations where the esophagus is not available, the only way to restore continuity is a high anastomosis, with the hypo-pharynx or even the oro- pharynx, at 


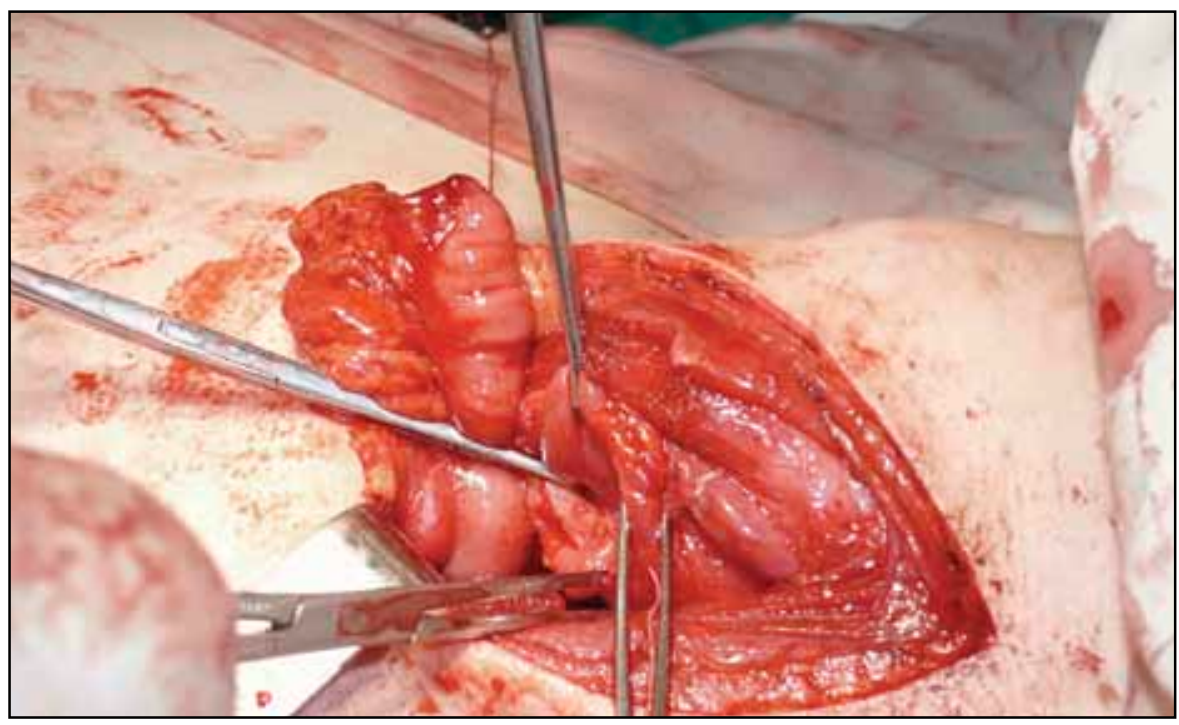

Figure 2 T-L eso-colic anastomosis. To be noted the suture on the teniae coli and the control of the esophageal caliber

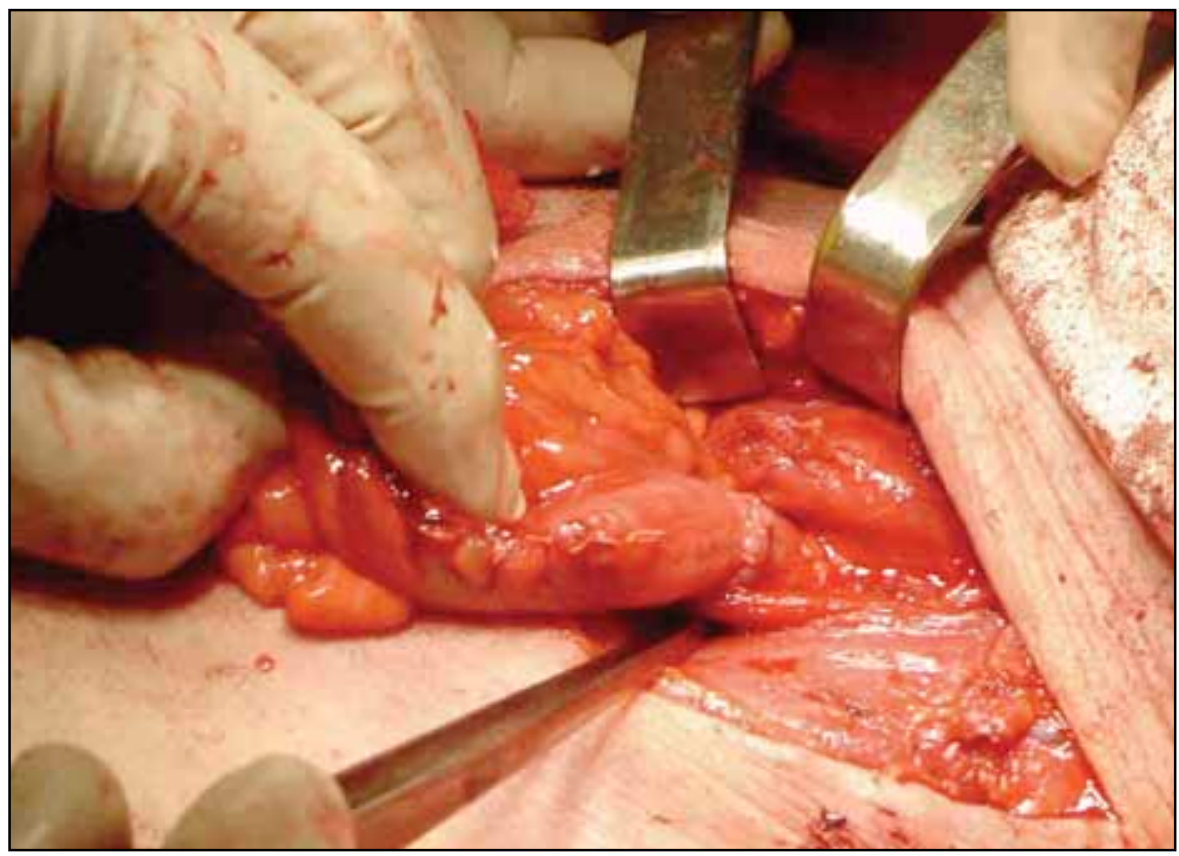

Figure 3 Final aspect of a T-L monolayer eso-colic anastomosis, with separate threads

the base of the tongue. As much as we want to avoid ascending the anastomosis line, the severe lesion involvement of the transition area hypo-pharynx - cervical esophagus imposes this conduct.

As a consequence, the status of the hypopharynx has an important role (Figure 4). Two types of endoscopic classification of hypopharyngeal disabling lesions are described:

- type I- the hypopharynx is partially stenosed (one or both pyriform sinuses maintain their normal structure), the oropharynx presents some strictures, the valleculae are free, the epiglottis is partially moved towards the lateral pharyngeal wall, and a plug inserted into the sphincter shows the obliteration of the cricopharyngeal sphincter;

- type II-severe fibrosis, the fusion of the tongue base with the posterior and lateral wall, the disappearance of valleculae, the epiglottis is reduced to a relic; there may be a passage through which one can observe the laryngeal vestibule, which is usually preserved, but vocal cord mobility is reduced by fusion of the aryepiglottic folds, and both pyriform sinuses are completely stenosed.

These two types must be clearly highlighted preoperatively, since they involve a different surgical approach. 


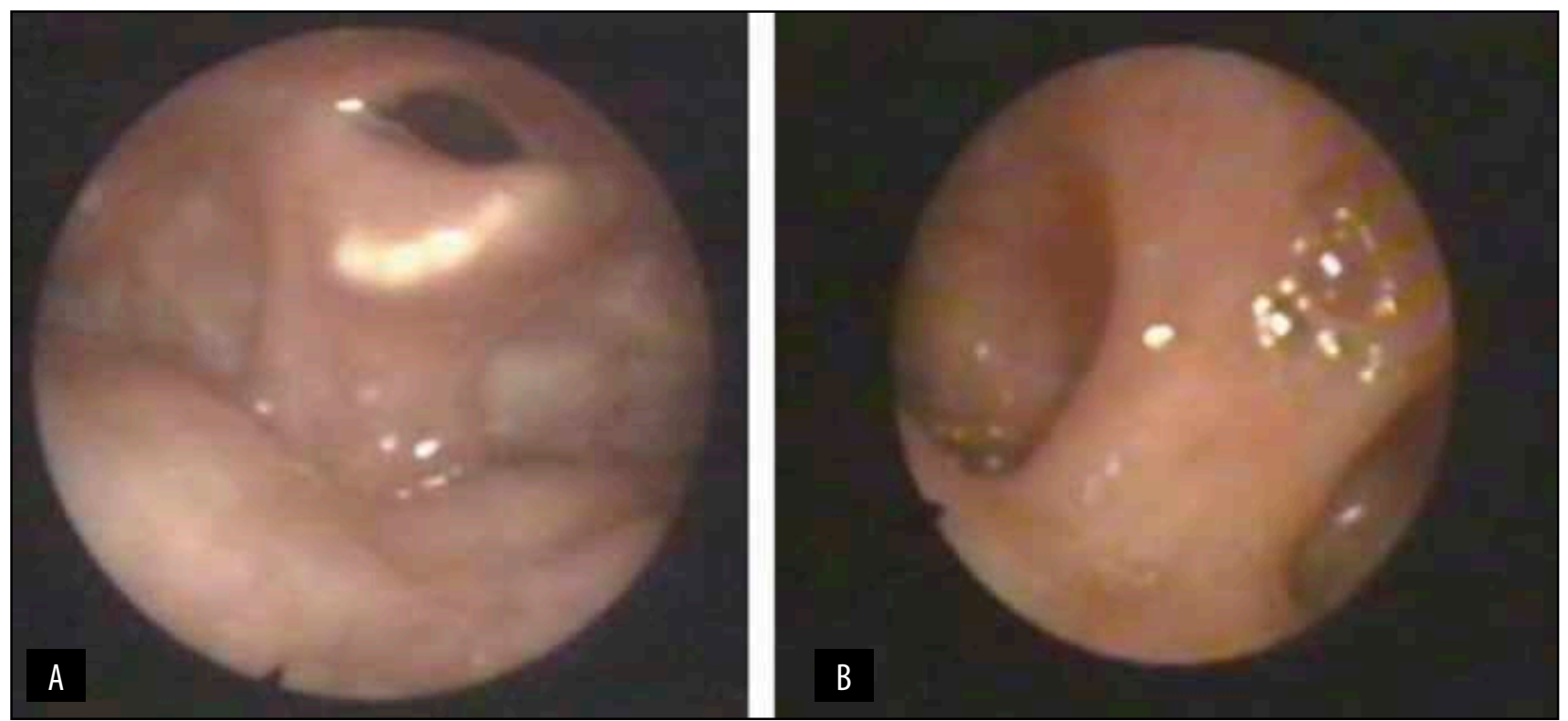

Figure 4 A - Preoperative fiberoptic laryngoscopy evaluation - It highlights the severe fibrosis, the epiglottis reduced to a relic; the laryngeal vestibule can be visualized. B - fiberoptic laryngoscopy evaluation - type II, severe fibrosis, with stenosis of the pyriform sinuses

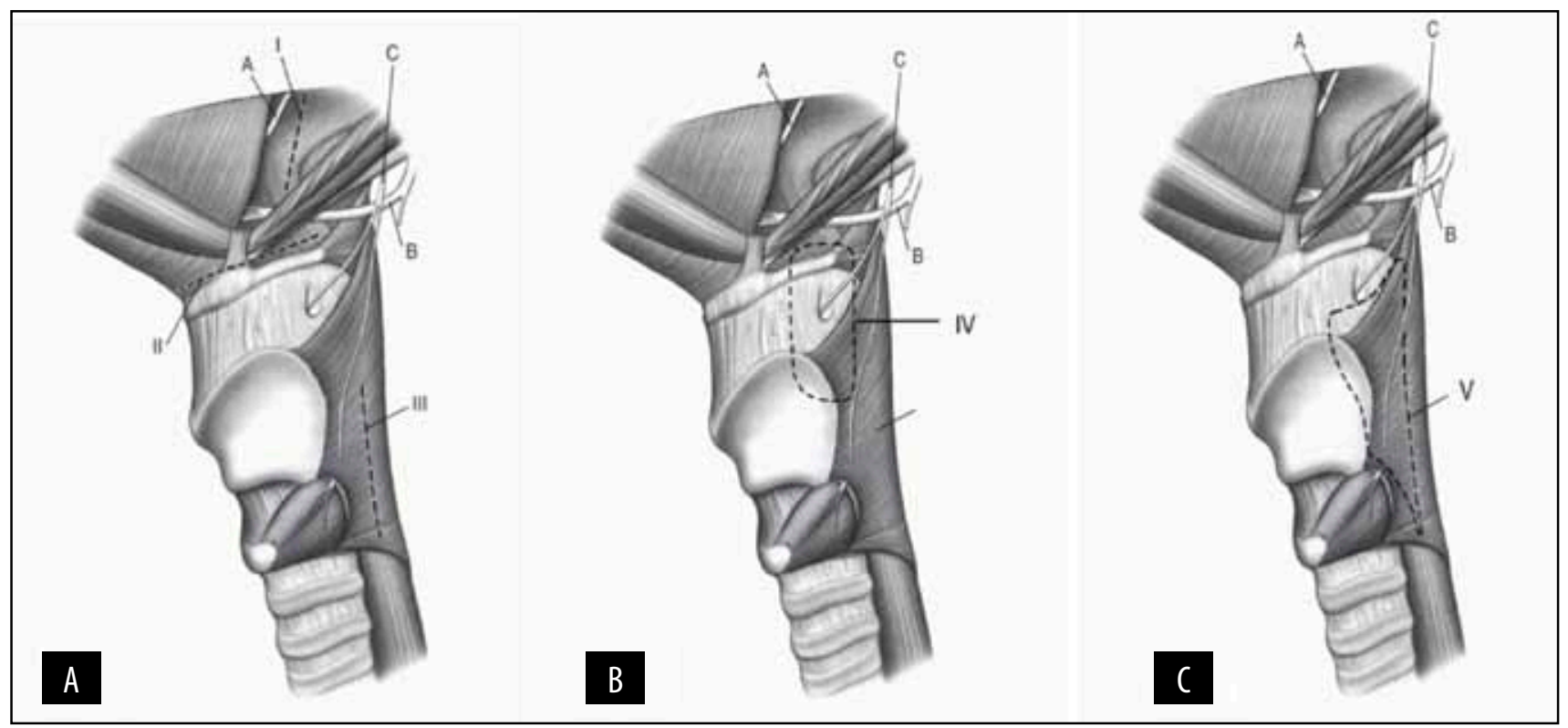

Figure 5 Types of pharyngotomies. A) Three variants described by D.Gavriliu: I - trans-epiglottic, II - in the hyoid bone bed, III - classic; B) Z. Popovici variant - IV; C) Laccourreye-Dubost variant - V. Nervous elements: $A=n$. lingual, $B=n$. hypoglossal, $C$. laryngeus superior

Several variants of pharyngotomies are described $^{28-31}$, the option for one or the other depending on the preferences, the surgical school or the intraoperative situation (the first three are described by D. Gavriliu) - Figure 5:

- trans-epiglottic pharyngotomy - opens the oropharynx above the hyoid bone, on a transversal line;

- transhyoid pharyngotomy - after resection of the left part of the hyoid bone, a transverse incision is performed in the pharynx, which prolabates beneath it;

- classic pharyngotomy - lateral to the thyroid car- tilage wing, with partial sectioning of the inferior constrictor of the pharynx muscle (the thyreopharyngicus muscle level);

- Z. Popovici pharyngotomy - an elliptical incision in the lateral pharyngeal wall after resection of the left part of the hyoid bone and the superior horn of the thyroid cartilage;

- Laccourreye-Dubost pharyngotomy - elliptical pharyngotomy extended into the inferior constrictor muscle of pharynx (the thyreopharyngicus muscle and cricopharyngeus muscle level) after resection of the superior left horn of the thyroid cartilage. 
The disadvantages of high anastomoses are numerous, and the functionality of the digestive tract is the more affected as the anastomosis is placed higher. This is due, on the one side, to several laborious technical conditions, such as partial hyoid bone resection, the difficult identification of a convenient anastomotic region, avoiding the sectioning of the hypoglossus nerve or of other local nervous structures (lingual nerve, superior laryngeal nerve), etc ${ }^{32,33}$.

Any uninspired sectioning during dissection may compromise the pharyngeal phase of deglutition, of neurological or muscular cause, with minimal chance of functional recovery in the postoperative period. A difficult food passage is also due to a "baffle" produced by the anastomosis type, always latero-lateral (L-L) and exceptionally latero-terminal (L-T). The delayed progression through anastomosis, especially in case of a big bolus, usually fluid, results in the accumulation of the content at the bottom of the hypopharyngeal sac, with aspiration into the airways. The higher the anastomosis, so closer to the glottal valve area, the higher the level of the accumulation column; therefore, there is an increased risk for tracheal aspiration ${ }^{34,35}$.

Should we also take into account the impaired deglutition due to severe caustic lesions or to reconstructive scar reshuffling, it is easy to understand why the functionality and recovery of the postoperative oro-gastric or colic passage function leaves much to be desired ${ }^{36}$ (Figure 6).

In our cases, all these findings have been confirmed, these patients being mainly those in whom the outcome was usually modest. For all these reasons, it is obvious that high anastomoses of the graft are addressed to some selected cases, where there is no other technical possibility.

If, in case of degradation by postfistular stenosis of the eso-visceral anastomosis, endoscopic approach is the golden standard procedure, the complication with minimal chances of resolution is the alteration of the swallowing mechanisms, usually in high anastomoses with the pharynx or in oro-pharyngeal burns, when permanent neuromuscular zonal lesions or disabling fibro-scleral ones occur. These patients remain dependent on a long-term joint assistance, surgical and ENT (repeated sessions of Laser, repermeabilization, dilations). The uncontrollable or unexplainable presence of a difficulty with varying degrees of the pharyngeal swallowing duration imposes a special program of swallowing re-education and re-learning conducted in the "Sfanta Maria" ENT Clinic. The "swallowing" assistance is an old practice in the Western world ${ }^{37-39}$ and, depending on the type of oropharyngeal dysfunction, patients should benefit from:

- identification of the postoperative dysphagia cause (neurological, motor);

- food management and assistance, with appor-

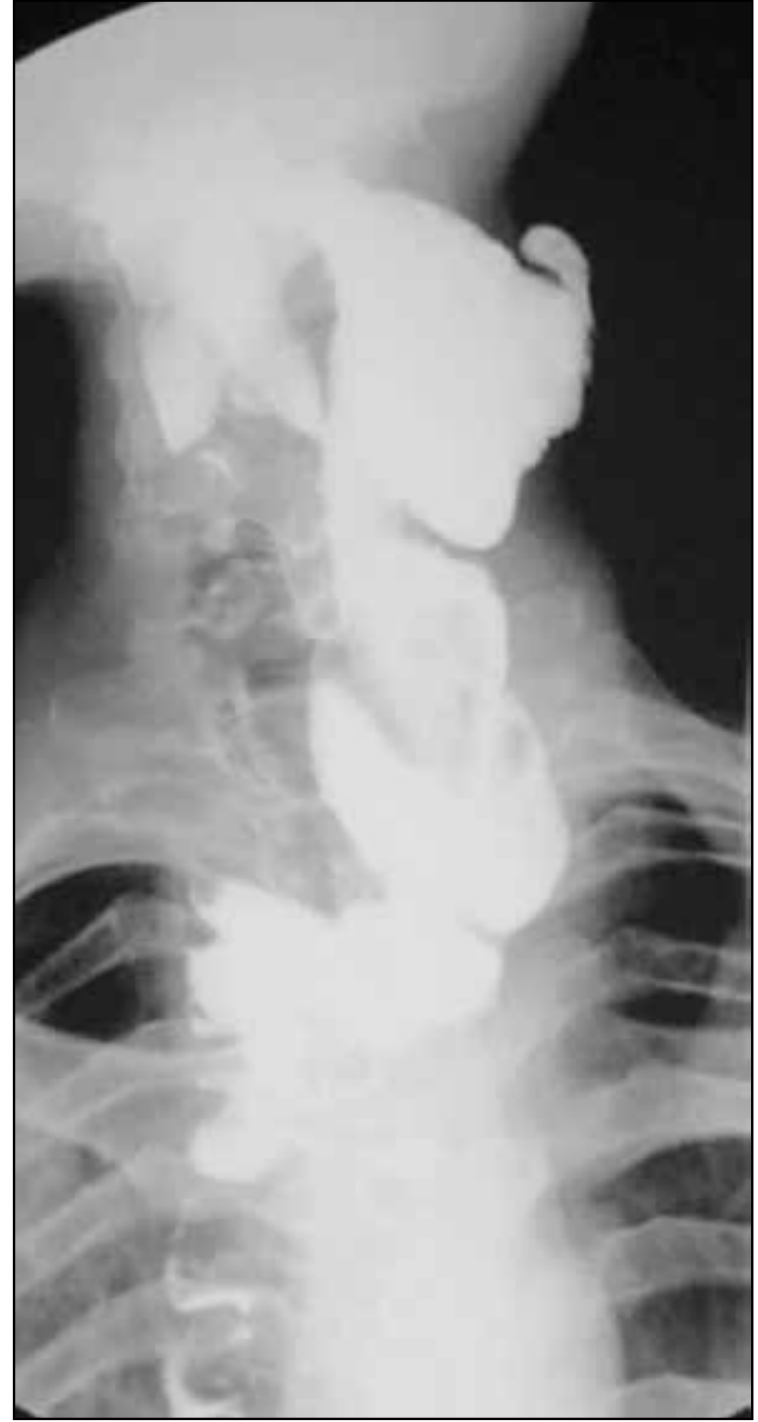

Figure 6 Contrast radiology, postoperative follow-up. One can notice a high anastomosis at the tongue base, with vallecular stasis through accumulation due to a difficult passage. Minimal tracheobronchial aspiration.

tionment according to food principles (solid, semisolid, liquid);

- techniques and methods for specific food and non-food neuromuscular training;

- neuromuscular electrical stimulation;

- oral-motor therapy exercises;

- Laser surgery for oro-pharyngeal intraluminal disabling lesions of fibrotic type;

- clinical and imaging periodic examinations (radiology, fiberoptic endoscopy).

Evidence of effective assistance results in a significant improvement in swallowing, especially in patients with an old feeding inability; they literally "forget" the voluntary act of swallowing. Re-education and re-learning of swallowing is however a process that takes time and determination, both from the patient and the ENT clinician. 


\section{CONCLUSIONS}

Esophageal reconstruction surgery remains a great challenge for any medical team.

Minimizing postoperative risks and complications requires a complete mastery of surgical methods, of the small technical "artifices" and of the necessary therapeutic refinements adapted to each individual case. One of the most important moments during the esophageal reconstruction surgery remains the duration of the cervical anastomosis, since the postoperative complication rate and the remote functional outcome depend on it.

The cervical anastomosis duration is essential for a good remote functional outcome. Using a neat, thorough technique and, whenever possible, the esophagus as proximal anastomotic partner, respectively the stomach or the left colon as distal partner, reduce the risk for fistula and healing through stenoses in up to about $6-8 \%$ of the cases.

T-T or T-L anastomoses are the correct option, and the number of additional anastomotic layers does not exempt the patient from the risk of fistula. The mechanical suture has not brought significant benefits. High anastomoses with the pharynx, regardless of the chosen technique, suppose a compromise: the significant relative risk of a difficult or at least hesitant feeding. The higher the anastomosis, so closer to the glottal valve area, the higher the level of the accumulation column; therefore, there is an increased risk for tracheal penetration. In postfistular stenosis of the esovisceral anastomosis, endoscopic resolution is the golden rule.

The alteration of the deglutition mechanisms, usually in high anastomoses with the pharynx or in case of oropharyngeal burns, when permanent neuromuscular zonal lesions or disabling fibro-scleral ones occur, imposes a long-term surgical and ENT assistance. The uncontrollable or unexplainable presence of a difficulty with varying degrees of the pharyngeal swallowing duration imposes a special program of swallowing re-education and re-learning ("swallowing" assistance).

\section{Conflicts of interests: None.}

Contribution of authors: All authors have equally contributed to this work.

\section{REFERENCES}

1. Fourquier P. - Prise en charge chirurgicale des brûlures caustiques de l'axe aéro-digestif supérieur chez l'adulte; à propos d'une série de 935 patients (Thèse). Paris, France: Universite Paris 6, 1993;pp.73.

2. Gumaste V.V., Dave P.B. - Ingestion of corrosive substances by adults. Am J Gastroenterol., 1992;87(1):1-5.
3. Kikendall J.W. - Caustic ingestion injuries. Gastroenterol Clin North Am., 1991;20(4):847-857.

4. Howell J.M., Dalsey W.C., Hartsell F.W., Butzin C.A. - Steroids for the treatment of corrosive esophageal injury: a statiscal analysis of past studies. Am J Emerg Med., 1992;10(5):421-425.

5. Gehanno P., Guedon C., March C., Lallemant Y. - Modèle expérimental d'étude des sténoses caustiques de l'oesophage et de leur prévention. Essai de la d-penicillamine. Ann Oto-Laryngol., 1978;95:373-378.

6. Predescu D., Constantinoiu S. - Probleme și dificultăți ridicate de reconstrucția esofagiană. Chirurgia, 2002;97(2):187-201.

7. Hugh T.B., Meagher A.P., Li B. - Gastric antral patch esophagoplasty for extensive corrosive stricture of the oesophagus. World J Surg., 1991;15(2):299-303.

8. Kennedy A.P., Cameron B.H., McGill C.W. - Colon patch esophagoplasty for caustic esophageal stricture. J Pediatr Surg., 1995;30(8):1242-1245.

9. Luoma R., Raboei E. - Colon-patch oesophagoplasty. Eur J Pediatr Surg., 2000;10(3):194-196.

10. Raboei E.H., Luoma R. - Colon patch esophagoplasty: an alternative to total esophagus replacement? Eur J Pediatr Surg., 2008;18(4):230-232.

11. Rosenblum J.D., Boyle C.M., Schwartz L.B. - The mesenteric circulation. Anatomy and physiology. Surg Clin N Am., 1997;77(2):289-306.

12. Ross J.A. - Vascular patterns of small and large intestine compared. Br J Surg., 1952;39(156):330-333.

13. Rădulescu D. - Caiete de chirurgie practică: Perete abdominal, tub digestiv, căi biliare, Volume 1. (medic.) Editura Medicală, 1982.

14. Iannettoni M.D., Whyte R.I., Orringer M.B. - Catastrophic complications of the cervical esophagogastric anastomosis. J Thorac Cardiovasc Surg., 1995;110(5):1493-1500; discussion 1500-1.

15. Orringer M.B., Marshall B., Iannettoni M.D. - Eliminating the cervical esophagogastric anastomotic leak with a side-to-side stapled anastomosis. J Thorac Cardiovasc Surg., 2000;119(2):277-288.

16. Orringer M.B., Appleman H.D., Argenta L., Bove E., Cimmino V. Polypropylene suture in esophageal and gastrointestinal operations. Surg Gynecol Obstet., 1977;144(1):67-70.

17. Senyk J., Rank F. - Oesophageal tissue reaction to different suture materials. An experimental study in the cat. Scand J Thorac Cardiovasc Surg., 1978;12(3):265-273.

18. Bourne R.B., Bitar H., Andreae P.R., Martin L.M., Finlay J.B., Marquis F. - In-vivo comparison of four absorbable sutures: Vicryl, Dexon Plus, Maxon and PDS. Can J Surg., 1988;31(1):43-45.

19. Rodeheaver G.T., Powell T.A., Thacker J.G. - Mechanical performance of monofilament synthetic absorbable sutures. Am J Surg., 1987;154(5):544-547.

20. Watkins D.H., Prevedel A.E., Munro G.A. - Valvular esophagogastrostomy; a method of preventing peptic esophagitis following esophagogastric anastomosis. Surg Forum., 1955;5:328-333.

21. Dai J.G., Liu Q.X., Den X.F., Min J.X. - Oesophageal flap valvuloplasty and wrapping suturing prevent gastrooesophageal reflux disease in dogs after oesophageal anastomosis. World J Gastroenterol., 2014;20(46):17434-17438. doi:10.3748/wjg.v20.i46.17434.

22. Zhi H.X., Ma J.S., Wang S.Y., Cao J.F., Han X.C., Zhou F.Y., Shi X.T., Mei P. - Intussusception anastomosis of the esophagus: a new method of anastomosis after resection of esophageal or cardiac carcinoma. J Surg Oncol., 1989;42(3):161-164.

23. Liu K., Zhang G.C., Cai Z.J. - Assessment of "tunnel" esophagogastrostomy based on laboratory findings, clinical analysis and 24-hour esophageal pH monitoring. Dis Esoph., 1991;4:111-117.

24. WongJ., Cheung H., Lui R., Fan Y.W., Smith A., Siu K.F. - Esophagogastric anastomosis performed with a stapler: the occurrence of leakage and stricture. Surgery, 1987;101(4):408-415.

25. Chassin J.L. - Stapling technic for esophagogastrostomy after esophago- 
gastric resection. Am J Surg., 1978;136(3):399-404.

26. Muller J.M., Erasmi H., Stelzner M., Zieren U., Pichlmaier H. - Surgical therapy of esophageal carcinoma. Br J Surg., 1990;77:845-857.

27. Bird P., Daniel F., MacLellan D. - Oesophagogastrectomy with an anastomosis using linear staplers. Aust N Z J Surg., 1996;66(11):757-763.

28. Gavriliu D. - Chirurgia esofagului. Ed. Medicală, Bucuresti, 1957.

29. Laccourreye H., Dubost C., Célerier M. - La pharyngotomie pour anastomose colique lors de l'œsophagoplastie totale. J Chir (Paris), 1974;107(1):83-86.

30. Popovici Z. - Results of pharyngoesophageal reconstruction in extensive corrosive strictures. The rationale of total reconstruction of the pharynx by ileal and colic interposition. Chirurgie, 1998;123(6):552-559.

31. Popovici Z. - Aspecte particulare ale coloesofagoplastiei în stenozele esofagiene postcaustice. Rev Chir Oncol Radiol O R L Oftalmol Stomatol Chir., 1976;25(6):409-417.

32. Borst H.G., Dragojenic D., Stegman T., Hetzer R. - Anastomotic leakage, stenosis and reflux after esophageal replacement. World J Surg., 1978;2:861-866.

33. Katariya K., Harvey J.C., Pina E., Beattie E.J. - Complications of transhiatal esophagectomy. J Surg Oncol., 1994;57(3):157-163.
34. Dodds W.J., Mann K.M., Cook I.J., Kahrilas P.J., Stewart E.T., Kern M.K. - Influence of bolus volume on swallow-induced hyoid movement in normal subjects. AJR Am J Roentgenol., 1988;150(6):1307-1309.

35. McConnel F.M.S., Mendelsohn M.S., Logemann J.A. - Manofluorography of deglutition after supraglottic laryngectorny. Head Neck Surg., 1987;9(3):142-150

36. Logemann J.A., Kahrilas P.J., Begelman J., Dodds W.J., Pauloski B.R. Interactive computer program for biomechanical analysis of videoradiographic studies of swallowing, AJR, 1989;153(2):277-280.

37. Mepani R., Antonik S., Massey B., Kern M., Logemann J., Pauloski B., Rademaker A., Casterling E., Shaker R. - Augmentation of deglutitive thyrohyoid muscle shortening by the shaker exercise dysphagia Dysphagia, 2009;24(1):26-31. doi: 10.1007/s00455-008-9167-y.

38. Han T.R., Kim H.R., Kim S.J. - Dysphagia development after surgery unrelated to laryngeal and pharyngeal structures. Dysphagia, 2009;24(2):167-171. doi: 10.1007/s00455-008-9188-6

39. Cohen A.K. - Creating a Swallow Screening Program at Mass General Hospital: A Model for Development and Implementation - Perspectives on Swallowing and Swallowing Disorders. Dysphagia, 2009;18:123-128. doi: 10.1044/sasd18.4.123. 